\title{
Allozyme polymorphisms in horseshoe crabs, Carcinoscorpius rotundicauda, collected from polluted and unpolluted intertidal areas in Peninsular Malaysia.
}

\begin{abstract}
It has been widely reported that allozyme frequency variation is a potential indicator of heavy metal-induced impacts in aquatic populations. In the present study, wild populations of horseshoe crab (Carcinoscorpius rotundicauda) were collected from contaminated and uncontaminated sites of Peninsular Malaysia. By adopting horizontal starch gel electrophoresis, seven enzyme systems were used to study allozyme polymorphisms. Nine polymorphic loci were observed in C. rotundicauda. The relationships of allozyme variations with the concentrations of $\mathrm{Cd}, \mathrm{Cu}, \mathrm{Ni}$, and $\mathrm{Zn}$ in sediments and in muscle tissues of horseshoe crabs were determined. Based on genetic distance, the lower mean value of Nei's D (0.017) indicated that both of the contaminated populations of Kg. Pasir Puteh and Kuala Juru were very closely related when compared to the relatively uncontaminated Pantai Lido population. Higher heterozygosities were shown by the contaminated populations when compared to the uncontaminated population. Different allelic frequencies could be observed for the aldolase (ALD; E.C. 2.7.5.1) locus between the contaminated and uncontaminated populations of $\mathrm{C}$. rotundicauda. The dendrogram of genetic relationships of the three populations of $\mathrm{C}$. rotundicauda showed the same clustering pattern as the dendrograms are based on heavy metals in the sediments and in the horseshoe crabs' abdominal muscles. From the F statistics, the present study showed that the three populations of horseshoe crabs were considered to have undergone moderate genetic differentiation with a mean F (ST) value of 0.092 .The current results suggest that allozyme polymorphism in horseshoe crabs is a potential biomonitoring tool for metal contamination, although further validation is required.
\end{abstract}

Keyword: Carcinoscorpius rotundicauda; Heavy metals; Peninsular Malaysia; Allozymes. 